\title{
Preparation and characterization of monoliths covalently bonded chelating groups for capillary electrochromatographic separation of metal ions
}

\author{
Guan-Ren Wang, Kuan-Pin Huang, Bao-Yu Huang, Chuen-Ying Liu* \\ Department of Chemistry, National Taiwan University, 1, Sec. 4, Roosevelt Road, Taipei 10617, Taiwan
}

\section{A R T I C L E I N F O}

\section{Article history:}

Received 31 March 2009

Received in revised form 25 June 2009

Accepted 10 July 2009

Available online 17 July 2009

\section{Keywords:}

Capillary electrochromatography

Chelating groups

Metal ions

Monolithic column

Stationary phase

\begin{abstract}
A B S T R A C T
In this work, a novel polymer-based monolithic column was prepared using an o-phthalaldehyde-Lphenylalanine Schiff base complex as the reactive center and a mixture of methanol and $n$-propanol as the porogen. The monolithic column was employed for the separation of a metal ion mixture including $\mathrm{Pb}(\mathrm{II}), \mathrm{Mn}(\mathrm{II}), \mathrm{Cu}(\mathrm{II}), \mathrm{Ni}(\mathrm{II}), \mathrm{Cr}(\mathrm{III}), \mathrm{Fe}(\mathrm{III})$ and $\mathrm{Cr}(\mathrm{VI})$. Tetrabutylammonium bromide (TBAB) was used as a mobile phase additive to enhance the separation efficiency of metal ions by EDTA precomplexation. Using a phosphate buffer $(20 \mathrm{mM}, \mathrm{pH} 3.0), \mathrm{TBAB}(10 \mathrm{mM}), \mathrm{MeOH}(15 \%, \mathrm{v} / \mathrm{v})$, an applied voltage of $-15 \mathrm{kV}$, and detection at $220 \mathrm{~nm}$, the metal ion mixture was satisfactorily resolved. The average theoretical plate number was 17,900 plates $/ \mathrm{m}$. The separation was also carried out in the absence of TBAB, leading to dissimilar elution order and shorter retention time. The separation behavior of the monolithic column was also compared with that of the blank polymer. The unique properties of the monolithic column might be mediated by a combination of electrophoretic behavior and chromatographic retention involving hydrophobic and hydrophilic interactions, as well as ligand exchange.
\end{abstract}

(c) 2009 Elsevier B.V. All rights reserved.

\section{Introduction}

Improving separation selectivity is of fundamental importance in separation science. Manipulation of the selectivity can be achieved by varying either the $\mathrm{pH}$ or the composition of the mobile phases and the stationary phases. Separation of most metal ions by $C E$ is complicated by their similar electrophoretic mobilities and their weak UV absorption. Investigation the CE separation of metal cations in the presence of various complexing agents has been reported by Conradi et al. [1]. They found that the separation of strong EDTA complexes is more difficult than that of the other weaker complexes. In recent years, there has been increasing interest in the CE separation of metal ions. Some excellent review articles related to these topics have attracted special attention [2-6].

Several groups have reported on the use of wall-coated capillaries for the CEC resolution of metal ions. Examples to be mentioned include dialkylimidazolium-based ionic liquid as a covalent coating reagent for the separation of metal ions [7]. Also, a highly selective chelating agent, hydroxamic acid, has been introduced for the separation of transition metal ions [8]. An anion complexone, macrocyclic polyamine has also been developed for the highly selective separation of metallocyanides, molybdate and tungstate

\footnotetext{
* Corresponding author. Tel.: +8862 33661645; fax: +886223638543.

E-mail address: cyliu@ntu.edu.tw (C.-Y. Liu).
}

[9]. Open-tubular columns are advantageous because of their easy preparation, the variety and availability of surface modification, and the lack of bubble formation. However, a potential drawback in using open-tubular CEC is the low phase ratio of the stationary phase.

Recent interest in monolithic columns as CEC stationary phases has arisen due to their advantages over packed-bed stationary phases. The monolith is formed in situ as a continuous bed within the capillary and can be covalently bound to the capillary wall. Both the simplicity of their in situ preparation and the large number of readily available chemistries make the monolithic separation columns an attractive alternative to the capillary columns packed with particulate materials. The use of monoliths for CEC separation of metal ions has so far received little attention. Only a few studies concerning the separation of inorganic ions were found in the literature. The first example of anion-exchange CEC using a monolithic silica column coated with poly(diallyldimethylammonium chloride) was reported [10]. These researchers subsequently used dextran sulfate in between multiple poly(diallyldimethyl-ammonium chloride)-coated monolithic silica for the separation of peptides and inorganic anions [11]. Recently, the use of a monolithic column coated with latex nanoparticles functionalized with quaternary ammonium groups for sample preconcentration and CEC separation of inorganic anions was reported $[12,13]$. The authors found a significant increase in the retention of the analytes compared to their latex-coated opentubular counterparts. 


\section{Step 1. Schiff base reaction}<smiles>C=CCSC(O)c1ccccc1C=O</smiles><smiles>C=CCSC(O)c1ccccc1C=O</smiles>

Step 2. Silanization

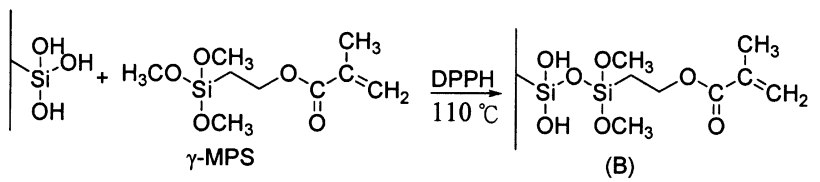

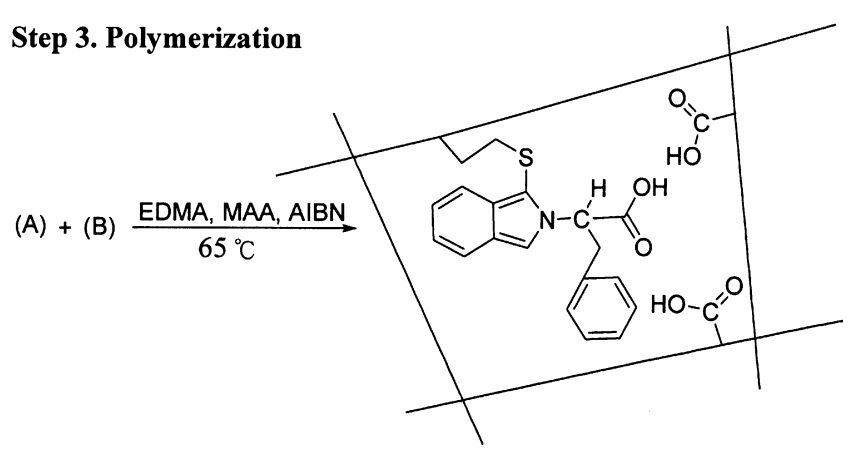

Fig. 1. Schematic of the procedures for column preparation.

Chelating ion exchanger shows highly selective than simple ion exchangers. The separations using it as stationary phases are termed chelation ion chromatography [14-16]. Nowadays, ion chromatography has derived considerable benefit from the introduction of porous monolithic media as stationary phase [17]. Examples are the works of metal-citrate complexes separated on monolithic column dynamically coated with $N$-(dodecyl- $N, N$ dimethylammonio)undecanoate [18], and alkali earth cations separated on monolithic silica column modified with sodium dioctyl sulfosuccinate [19]. Both are carried out with capillary column, but the mobile phases are not driven by electroosmotic flow.

The aromatic zwitterionic amino acid-phenylalanine is a good coordinating ligand. Although it has been introduced into the capillary column by different chemistry for the CEC separation of organic compounds and biomolecules [20-22], no related work on monolithic column was used for the CEC separation of metal ions. The main purpose of the present investigation was to evaluate the retention and separation selectivity of the prepared novel column. Tetrabutylammonium bromide (TBAB) was used as a mobile phase additive to enhance the separation efficiency.

\section{Experimental}

\subsection{Instrumentation}

All experiments were carried out in a laboratory-built unit. The unit consists of a $\pm 30 \mathrm{kV}$ high voltage power supply (EH 30P3, Glassman, USA) and a UV-Vis detector (LCD2083.2, ECOM, Czechoslovakia). Electrochromatograms were recorded and processed with CT-21 (Peak-ABC, Singapore). Fused silica capillaries (Polymicro Technologies, Phoenix, AZ, USA) were $75 \mu \mathrm{m}$ id, and the total length of the capillary was $70 \mathrm{~cm}$ with a distance of $50 \mathrm{~cm}$ between the injection and the detection window. The morphology of the prepared monolithic column was observed with an S-800 field emission scanning electron microscope (Hitachi, Tokyo, Japan).

\subsection{Reagents}

All chemicals were analytical reagent grade from Merck (Darmstadt, Germany), unless otherwise stated. Purified water $(18 \mathrm{M} \Omega-\mathrm{cm})$ from a Milli-Q water purification system (Millipore, Bedford, MA, USA) was used to prepare all solutions. Ferric chloride, o-phthalaldehyde (OPA), and ethylenegylcol dimethacrylate (EDMA) (Acros, Geel, Belgium), allylmercap$\tan (\mathrm{AM})$ and 3-trimethoxysilylpropylmethacrylate ( $\gamma$-MPS) (TCI, Tokyo, Japan), triethylamine (TEA), $\alpha, \alpha$-azobis(isobutyronitrile) (AIBN), lead nitrate, manganese sulfate pentahydrate, ferrous

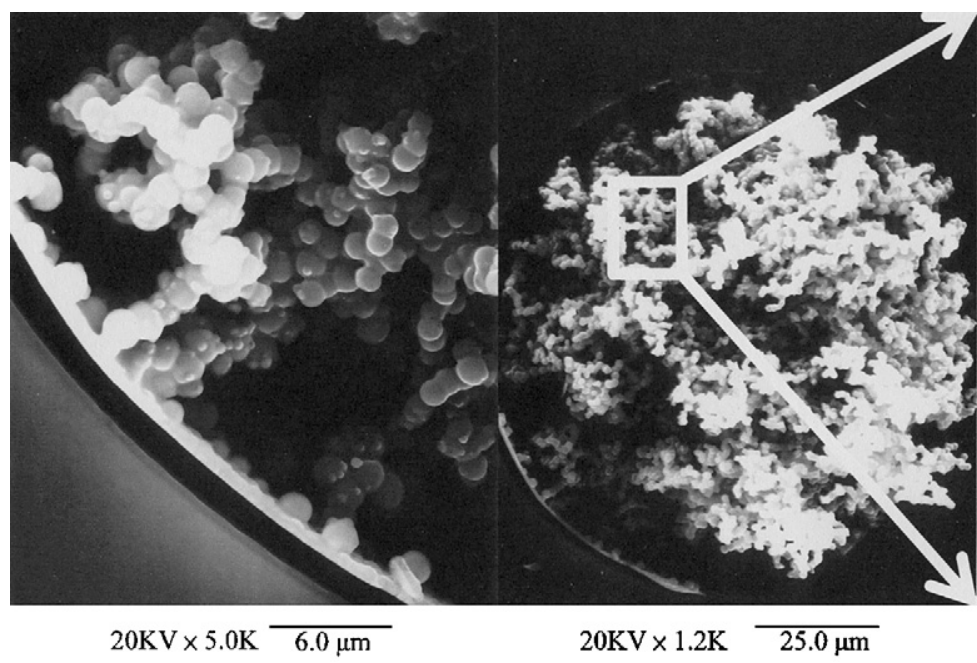

(a)

(b)

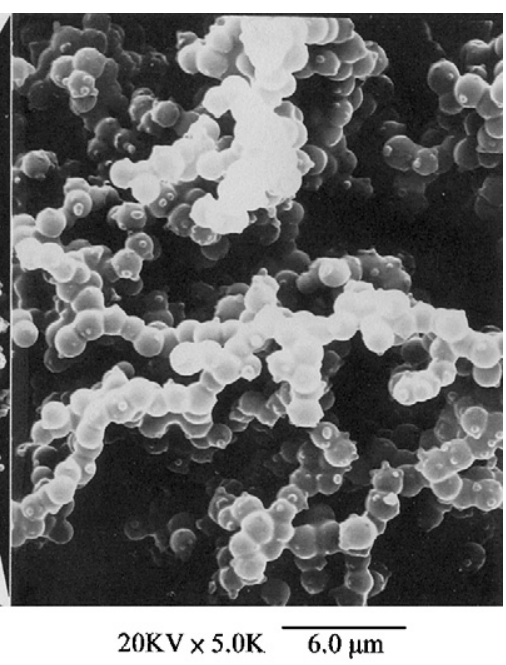

(c)

Fig. 2. SEM image of a polymer monolith capillary column: (a) side view, (b) top view, and (c) amplification of part of the image in (b). 


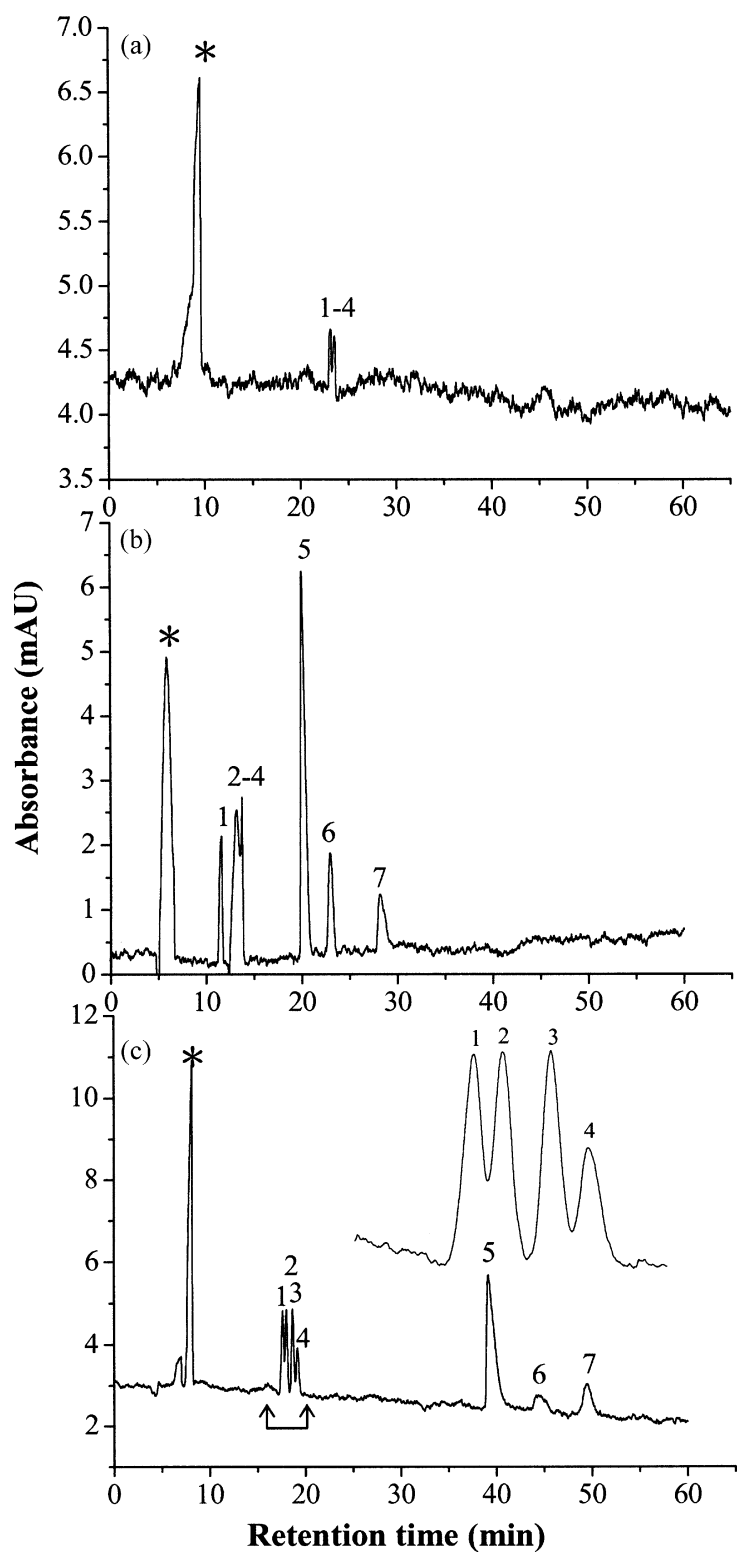

Fig. 3. Electrochromatograms of the metal ion separation at various buffers: (a) acetate buffer, (b) phosphate buffer, and (c) EDTA buffer. Conditions are as follows: monolithic column, $70 \mathrm{~cm}(50 \mathrm{~cm}$ effective length $) \times 75 \mu \mathrm{m}$ id; sample concentration: $\mathrm{Pb}$ (II) $(1.0 \mathrm{mM}), \mathrm{Mn}(\mathrm{II})(1.8 \mathrm{mM}), \mathrm{Cu}$ (II) $(1.0 \mathrm{mM}), \mathrm{Ni}(\mathrm{II})(1.0 \mathrm{mM}), \mathrm{Cr}$ (III) (1.0 mM), $\mathrm{Fe}(\mathrm{III})(0.2 \mathrm{mM}), \mathrm{Cr}(\mathrm{VI})(1.0 \mathrm{mM})$; hydrostatic injection $(10 \mathrm{~s}, 20 \mathrm{~cm})$; buffer (20 mM, pH 4.0)/TBAB (10 mM); applied voltage: $-15 \mathrm{kV}$; detection at $220 \mathrm{~nm}$. Peaks: $\left.{ }^{*}\right) \mathrm{NO}_{3}{ }^{-}$, (1) $\mathrm{Pb}(\mathrm{II}),(2) \mathrm{Mn}(\mathrm{II}),(3) \mathrm{Cu}(\mathrm{II}),(4) \mathrm{Ni}(\mathrm{II}),(5) \mathrm{Cr}(\mathrm{III}),(6) \mathrm{Fe}(\mathrm{III})$ and (7) $\mathrm{Cr}(\mathrm{VI})$. ammonium sulfate and copper chloride (Wako, Osaka, Japan), mesityl oxide (Aldrich, Milwaukee, WI, USA), L-phenylalanine (L-Phe) and 1,1-diphenyl-2-picrylhydrazyl (DPPH) (Sigma, St. Louis, MO, USA), chromium trioxide (JT Baker, Paris, KY, USA), methacrylic acid (MAA) (Lancaster, Lancashire, UK), ethylenediaminetetraacetic acid disodium salt dihydrate (EDTA) (Riedel-de Haën, Hanover, Germany), chromium nitrate and nickel chloride (Merck), and TBAB (Fluka, Hanover, Germany) were purchased as indicated. All solvents and buffers were filtered through a $0.45-\mu \mathrm{m}$ cellulose acetate membrane (Whatman, St. Louis, MO, USA).

\subsection{Column preparation}

The silanization of the capillary column has been previously described [23]. Briefly, the capillaries were filled with $\gamma$-MPS ( $40 \mathrm{mg})$ and DPPH $(0.1 \mathrm{mg})$ in $0.1 \%(\mathrm{v} / \mathrm{v}) \mathrm{TEA} /$ toluene $(1 \mathrm{~mL})$ by $\mathrm{N}_{2}$ flow $(0.16 \mathrm{MPa})$, then plugged with GC septa and reacted at $110^{\circ} \mathrm{C}$ for $12 \mathrm{~h}$. The column was rinsed with toluene to remove unreacted materials. The in situ polymerization and functionalization reaction in the silylated capillary was followed according to the published procedures [22], except that only MAA was used as the functional monomer and the template was not removed. Methanol $(10 \mathrm{~mL})$, OPA $(1 \mathrm{mmol})$, AM $(1 \mathrm{mmol})$, L-Phe $(1 \mathrm{mmol})$ and TEA ( $1 \mathrm{mmol})$ were added to the round-bottom flask $(25 \mathrm{~mL})$ and reacted with stirring at room temperature for $12 \mathrm{~h}$. Unreacted residue was removed by filtration. Then $n$-propanol $(10 \mathrm{~mL})$, MAA ( $2 \mathrm{mmol}$ ), EDMA (25 mmol), and AIBN (24.6 mg) were then added to the filtrate. After the mixture was completely dissolved under ultrasonication at a temperature lower than $10^{\circ} \mathrm{C}$, it was introduced into the capillary by $\mathrm{N}_{2}$ flow $(0.16 \mathrm{MPa})$. The capillary was then plugged with a GC septum and reacted at $65^{\circ} \mathrm{C}$ for $17 \mathrm{~min}$. The corresponding blank column was prepared analogously to the monolithic column but without L-Phe molecules.

\subsection{Capillary electrochromatographic conditions}

Before analysis, the monolithic columns were preconditioned with the running buffer. Between runs, they were rinsed with methanol, pure water and running buffer for 1 or 2 min intervals. Sample solutions were precomplexed with EDTA (10 mM, pH 4.0). The samples were injected by siphoning at a height difference of $20 \mathrm{~cm}$ for $10 \mathrm{~s}$. The samples were monitored at $220 \mathrm{~nm}$ with the UV absorbance detector.

\section{Results and discussion}

\subsection{In situ polymerization of monolithic column}

The monoliths were prepared from a methacrylate-based polymer with introducing a chelation group, L-Phe on the skeleton according to the procedures shown in Fig. 1. In order to produce a

Table 1

Physical properties of the tested metal ions.

\begin{tabular}{|c|c|c|c|c|c|}
\hline Analyte & Relative mobility $\left(\times 10^{-2}\right)^{\mathrm{a}}$ & $\log K_{f}^{\mathrm{b}}\left(\log K_{f}^{\prime}\right)^{\mathrm{c}}\left(\mathrm{EDTA}, \mathrm{Na}_{2} \mathrm{H}_{2} \mathrm{Y}\right)$ & $\log K_{f}^{\mathrm{b}}$ (acetic acid) & $\log K_{f}^{\mathrm{b}}$ (phosphoric acid) & $\log K_{f}^{\mathrm{b}}(\mathrm{L}-\mathrm{Phe})$ \\
\hline $\mathrm{Pb}(\mathrm{II})$ & -3.21 & $18.04(7.45)$ & 2.15 & 3.1 & 8.84 \\
\hline $\mathrm{Cu}(\mathrm{II})$ & -4.04 & $18.80(8.21)$ & 1.83 & 3.2 & 14.77 \\
\hline $\mathrm{Ni}(\mathrm{II})$ & -4.08 & $18.62(8.03)$ & 0.74 & 2.08 & 9.59 \\
\hline $\mathrm{Mn}(\mathrm{II})$ & -4.11 & $13.87(3.29)$ & 0.8 & - & 4.7 \\
\hline $\mathrm{Cr}(\mathrm{III})$ & -2.07 & $23.4(12.81)$ & 4.63 & 2.56 & - \\
\hline $\mathrm{Fe}(\mathrm{III})$ & -2.05 & $25.1(14.51)$ & 3.38 & 8.30 & 19.11 \\
\hline $\mathrm{Cr}(\mathrm{III})$ & - & - & - & - & - \\
\hline
\end{tabular}

${ }^{\text {a }} \mu_{\text {rel }}=Q / M^{2 / 3}$, where $Q$ (charge) and $M$ (molecular weight) are calculated from their metal-EDTA complexes, MY ${ }^{n-4}$, except Cr(VI) which does not form EDTA complex.

b Data from Ref. [34].

c The conditional formation constants of metal-EDTA complexes, MY ${ }^{n-4}$ are calculated at pH value of 3.0. 
covalent bond between the capillary wall and the monolithic polymer, silane with a vinyl group was employed for the silanization of the inner surface of the capillary column. DPPH was added as an inhibitor to avoid self-polymerization via the vinyl groups [24,25]. The fluidity of the column was tested with methanol injected by a syringe pump.

The polymerization process was found to be too fast when the heating temperature was above $85^{\circ} \mathrm{C}$. In this case, a yellowish white emulsified precipitate went through the column along with methanol, which resulted in only a thin polymerization layer. In a thermally initiated polymerization process, the temperature has to be controlled carefully, as it affects the rate of nucleation. Both the initiator decomposition rate and the propagation rate increase with temperature, causing the nuclei to grow larger [26]. To improve the polymerization process, a lower temperature of $65^{\circ} \mathrm{C}$ was chosen for the reaction. The typical morphology of a continuous skeleton and relatively large pores was observed by SEM (Fig. 2), and the boundary between the polymer monolith and the inner wall of the capillary was very smooth (Fig. 2a). Also, uniform ball-shaped fine particles grew within the capillary, as shown in Fig. 2c (the amplification of a portion in Fig. 2b).

\subsection{Analytical application of the monolithic column}

The metal ions were precomplexed by the polydentate ligand EDTA. For the separation of negatively charged species in a reversed-phase column, TBAB is a good choice as an ion-pair reagent because it is univalent, aprotic, soluble and does not undergo aggregation or secondary equilibria $[27,28]$. In this work, the monolith was supposed to have some properties of a reversedphase column. TBAB was therefore used as the additive in the separation.

\subsubsection{Type of buffer}

The type of buffer solution is a very important parameter for metal ion separation. A suitable buffer should have a higher buffer capacity and strong complexing properties in order to maintain a constant $\mathrm{pH}$ and prevent metal ion hydrolysis. The phosphonate group has been shown to be a good ligand for metal ion separation [29]. We therefore tested acetate, phosphate and EDTA as the separation buffer, and the resulting electrochromatograms are shown in Fig. 3. With the acetate buffer, only two peaks were observed after the injection of seven metal complexes, while the phosphate and EDTA buffer demonstrated more satisfactory results. EDTA gave seven peaks of two divisions along with a longer retention time for the three ions eluted at later times.

Using buffers of identical concentrations (20 mM, pH 4.0), the ionic strength for these buffers are $3 \mathrm{mM}$ for acetate, $20 \mathrm{mM}$ for phosphate and $60 \mathrm{mM}$ for EDTA. In a high ionic strength medium, lower retention on the monolith would be observed. However, the retention observed in the present study increased in the order of acetate $<$ phosphate $<$ EDTA. This apparent contradiction may be explained by the fact that the mobile phases are not simple salts. Both the mobile phase and the stationary phase (L-Phe) are good coordinating ligands (Table 1 ). The isoelectric point ( $\mathrm{pI}$ ) of $\mathrm{L}-\mathrm{Phe}$ is 5.48. As pH values below 5, L-Phe has a positive charge. Both chelation and ion exchange might be involved in the separation. Since the metal ions are in the form of $\mathrm{MAc}^{n-1}, \mathrm{MPO}_{4}{ }^{n-3}$ and $\mathrm{MY}^{n-4}$, respectively with the mobile phase of acetate, phosphate and EDTA, the retention behavior is rational. By considering the analysis time, phosphate buffer was chosen for further experiments.

\subsubsection{Phosphate buffer concentration}

The higher the buffer concentration, the stronger the ionic strength is. The compressed double layer between the buffer solution and the capillary wall leads to a lower zeta potential and EOF. But a weaker ionic strength would lead to sample adsorption and poor sample stacking. By varying the buffer concentration $(10-40 \mathrm{mM})$ at $\mathrm{pH} 4.5$, the retention time of the analyte became shorter as the buffer concentration was increased. This was due to more displacement reactions occurring in the reactive center. When the concentration of the phosphate buffer was increased to $40 \mathrm{mM}$,

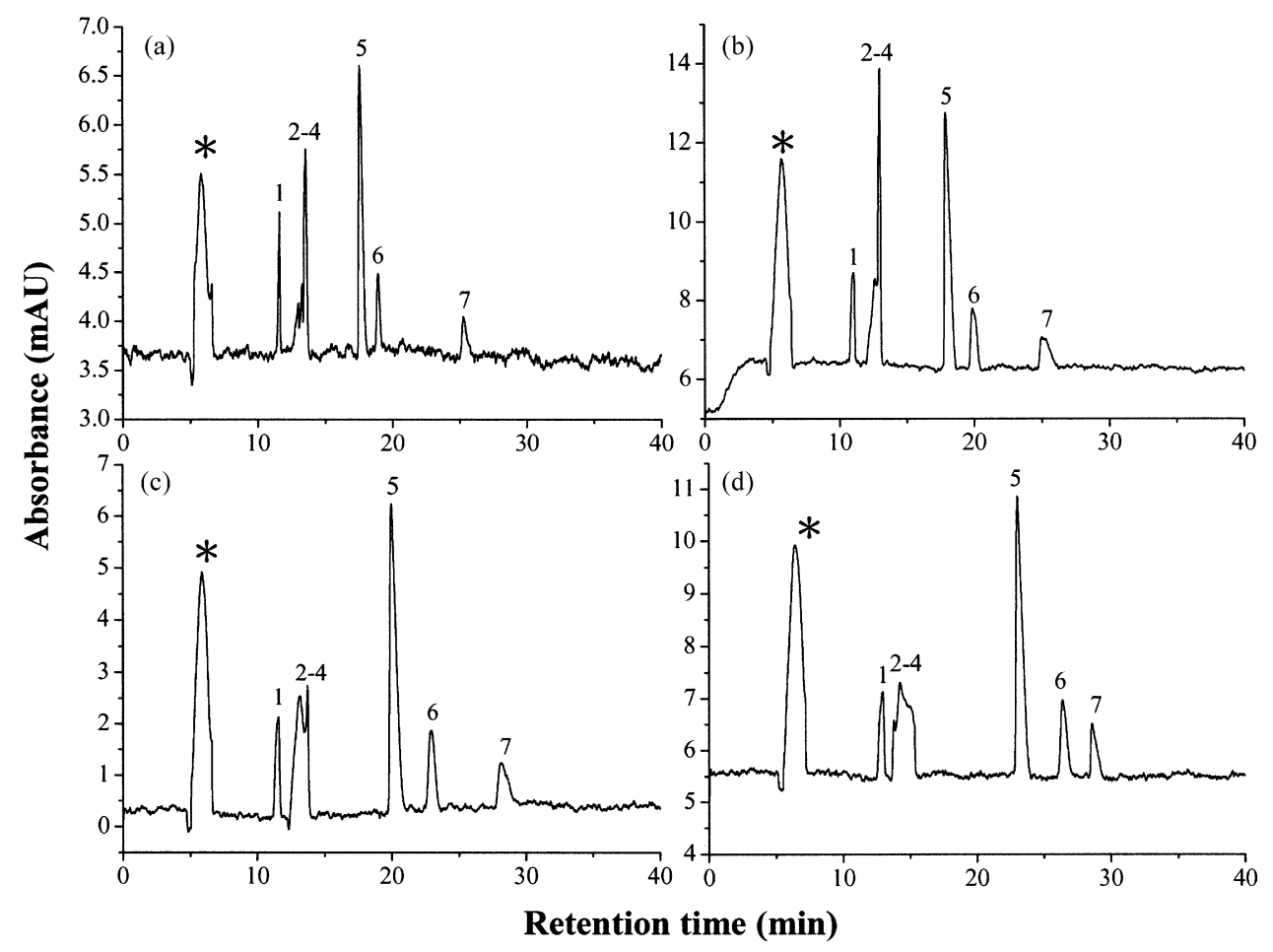

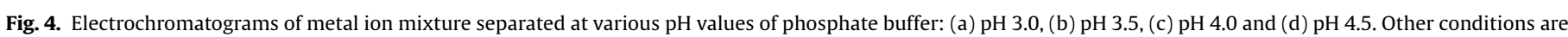
as shown in Fig. 3, except the buffer concentration was $20 \mathrm{mM}$ phosphate and $10 \mathrm{mM}$ TBAB. 
$\mathrm{Mn}(\mathrm{II}), \mathrm{Cu}(\mathrm{II})$ and $\mathrm{Ni}(\mathrm{II})$ coeluted. Therefore, a phosphate buffer of $20 \mathrm{mM}$ was chosen as the optimum.

\subsubsection{Phosphate buffer $p H$}

To maintain a positive reactive center in the monoliths, the $\mathrm{pH}$ was kept below the $\mathrm{p} I$ value of $\mathrm{L}$-Phe. The effect of the mobile phase $\mathrm{pH}$ on CEC separation was examined by varying the $\mathrm{pH}$ from 3 to 4.5. Fig. 4 shows the resulting electrochromatograms of the metal ion mixture using phosphate buffers of various $\mathrm{pH}$ values. As seen in Fig. 4, the analytes can be divided into two categories depending upon their behavior. In this narrow $\mathrm{pH}$ range, the EOF did not vary significantly. The results indicated that the silanol groups were highly silanized, and the magnitude of EOF attributed to the carboxylate groups of the monolithic polymer was suppressed. In fact, we injected benzyl alcohol, mesityl oxide and acetone, respectively from either the anode or cathode, we could not observe a marker signal longer than $1 \mathrm{~h}$. The increase in the retention time for the later eluted ions might be attributed to their greater formation constants with the L-Phe (Table 1 ). As the $\mathrm{pH}$ value increased, the resolution of peaks 2-4 improved slightly, although peak broadening occurred. To minimize peak broadening, $\mathrm{pH} 3.0$ was chosen for further evaluation.

\subsubsection{Addition of organic solvent}

Adding an organic solvent can change the dielectric constant of the buffer solution, thereby affecting the interaction between analytes and the stationary phase. Fig. 5 shows the influence of $\mathrm{MeOH}$ concentration on the retention behavior. As shown, increasing the concentration of $\mathrm{MeOH}$ caused a slight increase the resolution of peak 3 and 4. Complete separation was obtained when the $\mathrm{MeOH}$ concentration was $15 \%$. These results indicate that the separation of these metal complexes was mainly governed by the hydrophilic interaction between the metal complexes and the monolithic stationary phase at high concentration of $\mathrm{MeOH}$.

\subsubsection{Unexpected peak}

In this work, an unexpected peak $\left({ }^{*}\right)$ was found in all of the electrochromatograms. To identify the unknown peak, $1 \%(\mathrm{v} / \mathrm{v}) \mathrm{HNO}_{3}$, $\mathrm{H}_{2} \mathrm{SO}_{4}$ and $\mathrm{HCl}$, respectively was added to the analyte mixture. Only $\mathrm{HNO}_{3}$ resulted in an increase in intensity of the unknown peak. The distinction was explained by the fact that the absorptivities of $\mathrm{SO}_{4}{ }^{2-}$ and $\mathrm{Cl}^{-}$at $220 \mathrm{~nm}$ are much smaller than that of $\mathrm{NO}_{3}{ }^{-}$.

\subsection{Separation mechanism}

In this work, analytes were injected from the negative end. According to the relative mobility of metal-EDTA complexes shown in Table 1 , the elution order was expected to be $\mathrm{Mn}(\mathrm{II})>\mathrm{Ni}(\mathrm{II})>\mathrm{Cu}(\mathrm{II})>\mathrm{Pb}(\mathrm{II})>\mathrm{Cr}(\mathrm{III})>\mathrm{Fe}(\mathrm{III})$. However, the result did not follow this above-mentioned order, and we attribute these results to changes in the separation mechanism in addition to the electrophoretic difference. As stated earlier, L-Phe carries a positive charge below $\mathrm{pH}$ 5. The column likes an anion exchanger. Among the chromium species, only $\mathrm{Cr}(\mathrm{III})$ made a complex with EDTA, $\mathrm{Cr}(\mathrm{VI})$ exists as $\mathrm{HCrO}_{4}{ }^{-}$and $\mathrm{Cr}_{2} \mathrm{O}_{7}{ }^{2-}$ at $\mathrm{pH}$ 2-6 [30]. This property made the discrimination of chromium speciation possible. The hexavalent chromium anions retained in this anion-exchange column were eluted last in all cases.

\subsubsection{Effect of TBA on the separation efficiency}

To further explore the separation mechanism of the monoliths developed in this work, the following conditions were investigated: (1) no TBAB used in the process (Fig. 6a), (2) addition of TBAB in precomplexation (Fig. 6b), and (3) TBAB present both in precomplexation and the mobile phase (Fig. 6c).

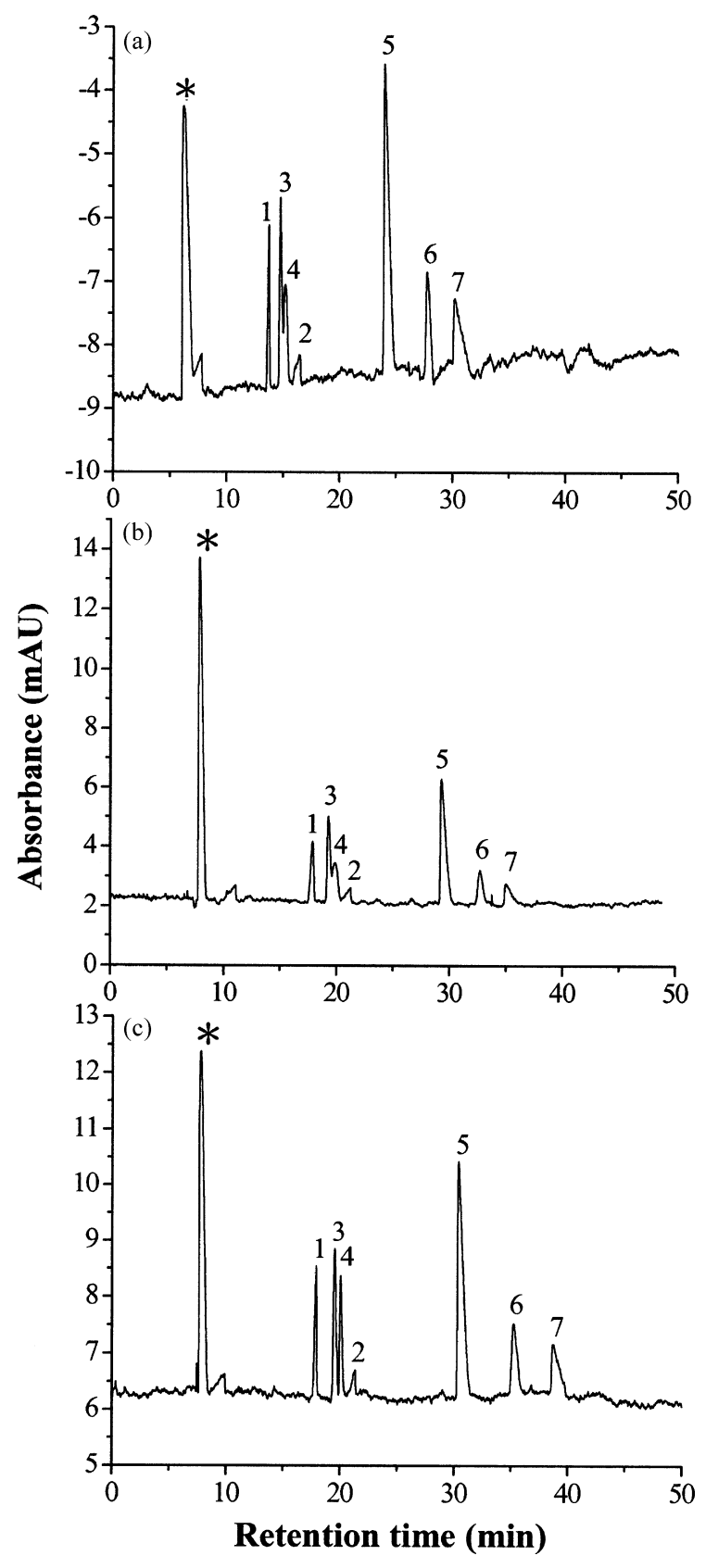

Fig. 5. Electrochromatograms of metal ion mixtures separated at different concentrations of methanol. Methanol was added at (a) $5 \%$, (b) $10 \%$ and (c) $15 \%$. Other conditions are as in Fig. 4, except the concentration of phosphate buffer was $20 \mathrm{mM}$, pH 3.0 with $10 \mathrm{mM}$ TBAB.

The retention time when no TBAB was used (Fig. 6a) was longer than that when TBAB was added in the precomplexation stage (Fig. 6b). This is due to the strong electrostatic affinity between the positive reactive center in the monoliths and the negative charge of the EDTA-metal complexes. The difference in the retention time was more pronounced for the latter eluted ions, which have greater ionic charges. Considering that TBAB exists both in precomplexation and in the mobile phase, an ion-pair-metal complex, $\left(\mathrm{TBA}^{+}\right)_{n}-\mathrm{MY}^{n-4}$ will be more accessible to react with the phenyl group of the reactive center. Additionally, $\mathrm{TBA}^{+}$can act as a counter ion for $-\mathrm{COO}^{-}$in the monoliths. Hence, a greater hydrophobic interaction between the analyte and the monoliths makes the retention time longest when TBAB is added to both precomplexation and the 

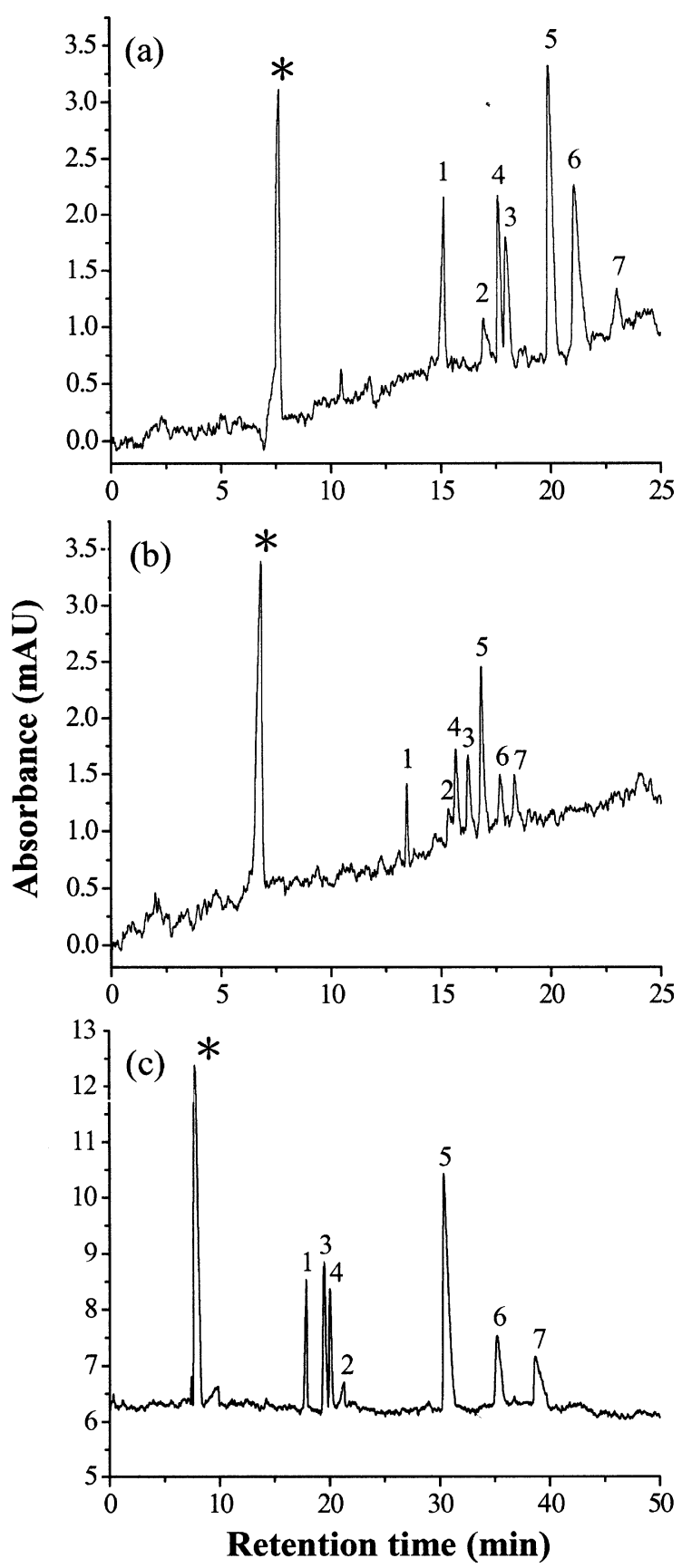

Fig. 6. Effect of TBAB on the separation. (a) No TBAB in all the process, (b) addition of TBAB $(10 \mathrm{mM})$ in precomplexation and (c) TBAB $(10 \mathrm{mM})$ present both in precomplexation and the mobile phase. Other conditions are as shown in Fig. $5 c$.

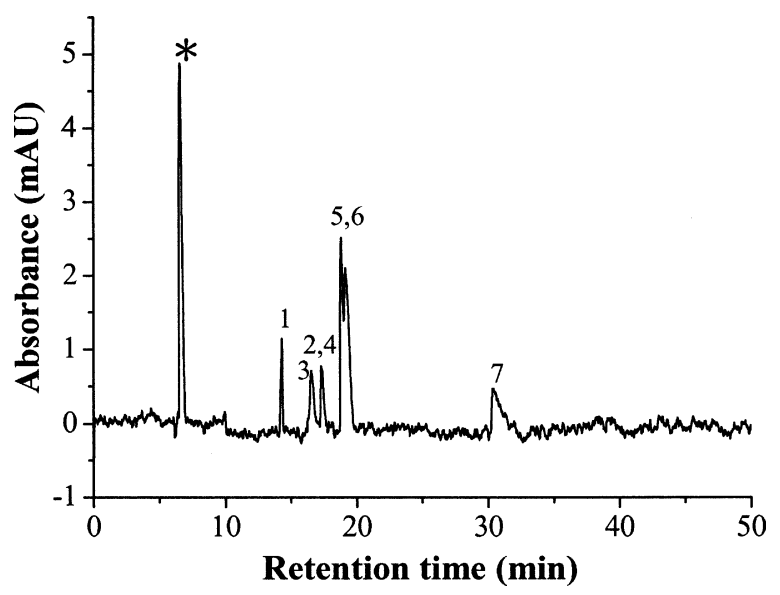

Fig. 7. Separation of metal ion mixture with blank polymer. Other conditions are as shown in Fig. 6c. Peaks: (*) $\mathrm{NO}_{3}{ }^{-}$, (1) $\mathrm{Pb}(\mathrm{II}),(2) \mathrm{Mn}(\mathrm{II}),(3) \mathrm{Cu}(\mathrm{II}),(4) \mathrm{Ni}(\mathrm{II}),(5) \mathrm{Cr}(\mathrm{III})$, (6) $\mathrm{Fe}(\mathrm{III})$ and (7) $\mathrm{Cr}(\mathrm{VI})$.

mobile phase (Fig. 6c). Meanwhile, the sequence between $\mathrm{Mn}(\mathrm{II})$, $\mathrm{Cu}(\mathrm{II})$ and $\mathrm{Ni}(\mathrm{II})$ was also observed to change. This suggests that the behavior responsible for the separation mechanism is different from that of the other two cases.

\subsubsection{Comparison between the retention behavior of the monolithic column and the blank monolithic polymer}

The selectivity of the novel monolith was further assessed by comparing it with a blank polymer under similar experimental conditions (Fig. 7). A longer retention time and better resolution for the analytes in the monolith were observed (Fig. 6c vs. Fig. 7), which was due to the presence of a chelating group, L-Phe. The partial resolution of these analytes in Fig. 7 might be attributed to the $-\mathrm{COOH}$ group on the polymer skeleton (Fig. 1).

Conradi et al. [1] have investigated the CE separation of EDTA metal complexes in the mix buffer $(\mathrm{pH} 4.01)$ of salicylic acid $(7.5 \mathrm{mM}) /$ EDTA $(0.1 \mathrm{mM}) /$ hexadecyltrimethylammonium bromide $(0.02 \mathrm{mM})$. But they cannot separate the mixture of $\mathrm{Fe}(\mathrm{III}), \mathrm{Pb}(\mathrm{II})$, $\mathrm{Cu}(\mathrm{II}), \mathrm{Ni}(\mathrm{II}), \mathrm{Zn}(\mathrm{II})$ and $\mathrm{Fe}(\mathrm{II})$ in a single run. We further compared with the CE separation of EDTA metal complexes in the literature. All of them needed cationic surfactants with long alkyl chain, cetyltrimethylammonium bromide [31] or tetradecyltrimethylammonium bromide [32] as well as other complex selector, vancomycin [33] in the buffer. The specific advantage of the present work over simple CE separation is that only phosphate buffer was needed. The baseline separation could be achieved even without the short chain ion-pair agent, TBAB (Fig. 6a). The unique properties of the new monolithic column and the proposed CEC system are highly promising, especially in the development of an on-line detection with ICPMS.

Table 2

Separation efficiency of the monolithic column ${ }^{\mathrm{a}}$.

\begin{tabular}{|c|c|c|c|c|}
\hline Analyte & Retention time (RSD\%) & Peak area ( $\mu V \mathrm{~s})(\mathrm{RSD} \%)$ & Resolution & Number of plates $(\mathrm{N} / \mathrm{m})$ \\
\hline $\mathrm{Pb}(\mathrm{II})$ & $18.45( \pm 2.49)$ & $29,500( \pm 5.35)$ & - & 22,400 \\
\hline $\mathrm{Cu}(\mathrm{II})$ & $18.85( \pm 3.72)$ & $42,500( \pm 4.63)$ & 1.39 & 30,800 \\
\hline $\mathrm{Ni}(\mathrm{II})$ & $19.60( \pm 3.33)$ & $44,400( \pm 4.95)$ & 0.86 & 20,500 \\
\hline $\operatorname{Mn}(I I)$ & $22.23( \pm 2.61)$ & $11,000( \pm 5.68)$ & 1.94 & 10,500 \\
\hline $\mathrm{Cr}(\mathrm{III})$ & $34.50( \pm 5.18)$ & $144,200( \pm 5.88)$ & 7.38 & 14,500 \\
\hline $\mathrm{Fe}(\mathrm{III})$ & $37.16( \pm 5.58)$ & $37,100( \pm 5.78)$ & 2.79 & 16,000 \\
\hline $\mathrm{Cr}(\mathrm{VI})$ & $41.74( \pm 3.80)$ & $41,600( \pm 3.64)$ & 1.84 & 10,700 \\
\hline
\end{tabular}

The reproducibility was investigated by comparison with the nitrate peak as the reference in each measurement

a Conditions are as in Fig. 6(c); the data were assayed from four measurements between days. 


\subsection{Reproducibility of the monolithic column}

The reproducibility for the monoliths was investigated by comparison with the nitrate peak as the reference. Under the optimized condition (phosphate buffer $20 \mathrm{mM}$, pH 3; TBAB $10 \mathrm{mM}$; МeOH 15\%, $\mathrm{v} / \mathrm{v}$; and applied voltage of $-15 \mathrm{kV}$ ), the relative standard deviation (RSD) of retention time was ranged from 2.49 to $5.58 \%$, while that of peak area was ranged from 3.64 to $5.88 \%$ (Table 2). The data were assayed from four measurements between days. The number of theoretical plates was between 10,500 and 30,800 plates $/ \mathrm{m}$. The column can be used for longer than 6 months with more than 1000 injections.

\section{Conclusion}

In this work, strongly complexing ligands were used for metal precomplexation in a CEC separation. The pretreatment step can eliminate the sample matrix effect. However, with highly stable metal complexes manipulating the separation selectivity can be more difficult than with weakly complexing ligands $[1,2]$. Hence, a mixed mode of novel polymeric monoliths was used to assess the potential for the CEC separation of these metal complexes. With L-Phe, the zwitterionic chelating substrates, $\mathrm{pH}$ can be used as a convenient factor to manipulate and optimize the degree of retention through the alteration of the metal complex formation. In order to suppress the ion exchange property of the - $\mathrm{COOH}$ group on the polymeric skeleton, most of the studies were investigated below $\mathrm{pH}$ 5 . Under this condition, L-Phe carries a positive charge. Since the complexing ligand was used as the mobile phase, ligand exchange between the mobile phase and the stationary phase would occur. Adding TBAB increases not only the affinity of metal complexes toward the hydrophobic reactive center, but also increases the hydrophobic interaction with the polymeric skeleton of the monolithic column. The resolution was found to improve somewhat with the addition of an organic modifier, possibly due to enhanced hydrogen bonding. Besides, $\mathrm{Cr}(\mathrm{III})$ and $\mathrm{Cr}(\mathrm{VI})$ have been speciated by the proposed system.

The development of new ion-exchangers continues to be one of the most challenging research goals in ion chromatography [17], especially in the chelating ion chromatography with electrophoretic mode. Based on the separation behavior, the newly developed stationary phase would be expected to have highly potential for the CEC separation of heavy metal ions in complex matrix samples.

\section{Acknowledgement}

The authors thank the National Science Council of Taiwan for financial support (Grant Nos. NSC 95-2113-M-002 and NSC 962113-M-002-023-MY3).

\section{References}

[1] S. Conradi, C. Vogt, H. Wittrisch, G. Knobloch, G. Werner, J. Chromatogr. A 745 (1996) 103

[2] M. Macka, P.R. Haddad, Electrophoresis 18 (1997) 2482.

[3] M. Chiari, J. Chromatogr. A 805 (1998) 1

[4] M.C. Boyce, P.R. Haddad, Electrophoresis 24 (2003) 2013.

[5] A.R. Timerbaev, Electrophoresis 25 (2004) 4008.

[6] A.R. Timerbaev, Electrophoresis 28 (2007) 3420

[7] W. Qin, S.F.Y. Li, J. Chromatogr. A 1048 (2004) 253.

[8] G.J. Chen, N.M. Lee, C.C. Hu, C.Y. Liu, J. Chromatogr. A 699 (1995) 343.

[9] C.Y. Liu, W.H. Chen, J. Chromatogr. A 815 (1998) 251.

[10] M.C. Breadmore, S. Shrinivasan, K.A. Wolfe, M.E. Power, J.P. Ferrance, B. Hosticka, P.M. Norris, J.P. Landers, Electrophoresis 23 (2002) 3487.

[11] M.C. Breadmore, S. Shrinivasan, J. Karlinsey, J.P. Ferrance, P.M. Norris, J.P. Landers, Electrophoresis 24 (2003) 1261.

[12] J.P. Hutchinson, P. Zakaria, A.R. Bowie, M. Macka, N. Avdalovic, P.R. Haddad, Anal. Chem. 77 (2005) 407.

[13] J.P. Hutchinson, E.F. Hilder, M. Macka, N. Avdalovic, P.R. Haddad, J. Chromatogr. A 1109 (2006) 10

[14] P. Jones, P.N. Nesterenko, J. Chromatogr. A 1213 (2008) 45.

[15] P. Jones, P.N. Nesterenko, J. Chromatogr. A 789 (1997) 413.

[16] C.Y. Huang, N.M. Lee, S.Y. Lin, C.Y. Liu, Anal. Chim. Acta 466 (2002) 161

[17] P.R. Haddad, P.N. Nesterenko, W. Buchberger, J. Chromatogr. A 1184 (2008) 456.

[18] E. Gillespie, D. Connolly, M. Macka, P.N. Nesterenko, B. Paull, Analyst 132 (2007) 1238.

[19] E.P. Nesterenko, P.N. Nesterenko, B. Paull, J. Chromatogr. A 1213 (2008) 62.

[20] J. Hu, C. Xie, R. Tian, Z. He, H. Zou, J. Sep. Sci 30 (2007) 891.

[21] L. Xu, Y. Sun, J. Chromatogr. A 1183 (2008) 129.

[22] C.C. Lin, G.R. Wang, C.Y. Liu, Anal. Chim. Acta 572 (2006) 197.

[23] S.C. Chuang, C.Y. Chang, C.Y. Liu, J. Chromatogr. A 1044 (2004) 229

[24] Y.C. Huang, C.C. Lin, C.Y. Liu, Electrophoresis 25 (2004) 554.

[25] Y. Lin, Y. Chen, R. Xiang, D. Ciuparu, L.D. Pfefferle, C. Horváth, J.A. Wilkins, Anal. Chem. 77 (2005) 1398.

[26] E.G. Vlakh, T.B. Tennikova, J. Sep. Sci. 30 (2007) 2801.

[27] T. Cecchi, J. Sep. Sci. 28 (2005) 549.

[28] S. Hou, M. Ding, J. Zhu, Talanta 75 (2008) 178.

[29] M.J. Shaw, P.N. Nesterenko, G.W. Dicinoski, P.R. Haddad, J. Chromatogr. A 997 (2003) 3.

[30] G.Y. Jung, Y.S. Kim, H.B. Lim, Anal. Sci. 13 (1997) 463.

[31] P. Kubáň, P. Kubáň, V. Kubáň, J. Chromatogr. A 836 (1999) 75.

[32] B. Baraj, M. Martínez, A. Sastre, M. Aguilar, J. Chromatogr. A 695 (1995) 103.

[33] J. Threeprom, W. Som-aum, J.M. Lin, Anal. Sci. 22 (2006) 1179.

[34] A.E. Martell, R.M. Smith, Critical Stability Constants, vol. 1, Plenum Press, New York, 1974 (vol. 3, 1976; vol. 4, 1977). 